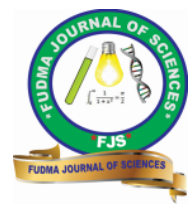

FUDMA Journal of Sciences (FJS)

ISSN online: $2616-1370$

ISSN print: 2645 - 2944

Vol. 4 No. 3, September, 2020, pp 697-703

DOI: https://doi.org/10.33003/fjs-2020-0403-253

\title{
EVALUATING THE SUN'S POSITION AND TRACKING THE SUN PATH FOR DUTSIN-MA, KATSINA STATE, NIGERIA
}

\author{
${ }^{1}$ Shehu M., ${ }^{2}$ Baraya J. T. \\ ${ }^{1}$ Department of Physics, Faculty of Science, Federal University Dutse, Jigawa State, Nigeria \\ ${ }^{2}$ Department of Physics, Federal University Dutsin-Ma, Katsina State, Nigeria \\ ${ }^{*}$ Corresponding Author's Email: shehumustapha44@gmail.com
}

\begin{abstract}
Solar energy is the most promising renewable energy source because of its free availability and an environmentally friendly source. The crucial applications of solar energy depend upon determining the precise position of the sun. In this research, we had made an attempt to determine the precise location of the sun for any topographical position of the earth using solar azimuth/altitude reckoner to track the path of the sun and related sun data. For the purpose of this work, we measured the position of Dutsin-Ma in Katsina State, Northwestern part of Nigeria. Solar online calculator (Keisan online calculator) was used to obtain primary data of sun's (solar) angle parameters in order to calculate a series of variations in the azimuth and altitude angles using some inputs such as latitude, longitude, date, year, time and time zone. The results revealed that the maximum azimuth angles obtained from the sun are $294.38^{\circ}$ for the winter solstice and $248.32^{\circ}$ for the summer solstice with elevation angles of $79.01^{\circ}$ and $53.46^{\circ}$ respectively. Furthermore, the highest values of the hour angles were found to be $97.05^{\circ}$ and $97.86^{\circ}$ for the summer solstice and the winter solstice respectively. The findings of this work will help individual, government, and non-governmental organizations towards the utilization of solar energy and harnessing it especially during the installations of solar panels and other solar devices.
\end{abstract}

Keywords: Solar energy, Azimuth angle, Altitude angle, Solar hour angle, Summer solstice, Winter solstice.

\section{INTRODUCTION}

The sun is one of the major energy sources in the earth. The energy released by the sun is known as solar energy or solar radiation (Lucien Wald, 2018). The power from the sun intercepted by the earth is over a trillion watt, which is many thousand times larger than the present consumption rate on the earth of all commercial energy sources. This implies that solar energy could supply all the present and future energy needs of the world on a continuous basis (Baraya et al., 2020). Nowadays solar energy becomes the most important source of energy because of its wider applications in all aspects of human endeavor. The current energy change is mainly towards encouraging the utilization of renewable energy resources for power generation, this is because they are environmentally friendly, broadly available, easily applicable, and nontoxic (Ajayi et al., 2014). Again, solar energy is found to be the most significant source of energy among the various renewable energy sources (Tikyaa et al., 2019).

Solar monitoring systems play a vital role in the improvement of solar energy applications, particularly in systems with high solar concentrations that directly exchange solar energy into electricity or heat (Luque and Viacheslav, 2007). MATLAB software was used to track the sun pathway and corresponding information such as sunrise and sunset (Salihi, 2012). A Computer program was advanced for maximum tracking of radiation with a solar dish by Arbab et al., (2009). Abdallah and Nijmeh (2004) used mathematical formulations to estimate the sun's movement and need not intelligence the sunshine. Yusie et al, (2013) utilized the application of the solar position algorithm to guesstimate the position of the sun using azimuth angle and zenith angle. Chen et al., (2006) developed a general sun-tracking formula for heliostats with arbitrarily oriented axes. Chong and Wong, (2009) offered on-axis sun-tracking formula to track the sun for accurate alignment. Analytical solutions for the three orientation angles using daily suntracking was obtained by Chong et al., (2009).

In this study, the sun's path and position for Dutsin-Ma will be traced during the summer and winter solstices for the year 2019.

\section{METHODOLOGY}

Primary data of solar parameters were obtained using the solar online calculator program. Keisan online computer calculator program was used and it was programmed in order to compute a sequence of variations in the solar elevation and azimuth angles the system is called ALTI-AZIMUTH. With an observant value, the system will compute the precise position and path of the sun for a day by inserting some inputs such as longitude, latitude, year, date, time zone, daylight saving time, etc. of the place.

Primarily, an exact location must be chosen by using its longitude and latitude followed by the height above sea level by means of a portable geographical positioning system (GPS) receiver, Dutsin-Ma town in Katsina State, Nigeria was chosen as an area of interest for this study with latitude $12.454480 \mathrm{~N}$ and longitude $7.497654 \mathrm{E}$ meanwhile the position of the sun must be recognized for single geographical point, where the observation will be carried out. Also, the remaining inputs; date, year, time zone, daylight saving time are also inserted in the Keisan calculator. Finally, after all, required data were entered then a start button was provided so that a table of 
EVALUATING THE SUN'S...

FJS

changes in the solar altitude and azimuth angles per day is displayed on the Keisan calculator monitor. The measurement was carried out from 4:00 in the morning to 19:00 in the evening at an interval of 30 minutes or half of an hour $(0.5$ hour). MATLAB was used to plot a graph of elevation angle, zenith angle, hour angle and azimuth angle each in degree against time in an hour to display the variations of these angles with time for that day. Three dissimilar graphs were plotted for different angles for unlike the route of the sun.

\section{RESULTS AND DISCUSSION}

The position of the sun's in the atmosphere can be expressed using an elevation angle and azimuth angle. A computer

\section{Shehu and Baraya}

software package has been verbalized which takes date and time as input and compute the solar elevation angle as well as the azimuth angle as an output for a specific topographical position. The program takes into consideration the day-to-day as well as the periodic difference of the solar path. Successively, for a given time and date, we can now trace the path of the sun follows at a specific position.

A total of thirty-two (32) measurements were analyzed in this work and the results shows that there is a significant change in the sun path at different dates and times of the year as displayed in the three tables below.

Table 1: Solar path for $\mathbf{2 6}^{\text {th }}$ May, 2019 for Dutsin-Ma.

\begin{tabular}{|c|c|c|c|c|c|}
\hline $\begin{array}{c}\text { Clock } \\
\text { Time (hr) }\end{array}$ & $\begin{array}{c}\text { Hour Angle } \\
\text { (Degree) }\end{array}$ & $\begin{array}{c}\text { Zenith Angle } \\
\text { (Degree) }\end{array}$ & $\begin{array}{c}\text { Elevation Angle } \\
\text { (Degree) }\end{array}$ & $\begin{array}{c}\text { Azimuth Angle } \\
\text { (Degree) }\end{array}$ & Solar Time (hr) \\
\hline 4.00 & -126.75 & 117.89 & -27.89 & 57.78 & 3.55 \\
\hline 4.50 & -119.25 & 111.58 & -21.58 & 61.11 & 4.05 \\
\hline 5.00 & -111.75 & 105.08 & -15.08 & 63.85 & 4.55 \\
\hline 5.50 & -104.25 & 98.44 & -8.44 & 66.11 & 5.05 \\
\hline 6.00 & -96.75 & 91.69 & -1.69 & 67.98 & 5.55 \\
\hline 6.50 & -89.25 & 84.87 & 5.13 & 69.52 & 6.05 \\
\hline 7.00 & -81.75 & 77.98 & 12.02 & 70.76 & 6.55 \\
\hline 7.50 & -74.25 & 71.04 & 18.96 & 71.72 & 7.05 \\
\hline 8.00 & -66.75 & 64.07 & 25.93 & 72.40 & 7.55 \\
\hline 8.50 & -59.25 & 57.09 & 32.91 & 72.78 & 8.05 \\
\hline 9.00 & -51.75 & 50.09 & 39.91 & 72.80 & 8.55 \\
\hline 9.50 & -44.25 & 43.10 & 46.90 & 72.33 & 9.05 \\
\hline 10.00 & -36.75 & 36.14 & 53.86 & 71.17 & 9.55 \\
\hline 10.50 & -29.26 & 29.26 & 60.74 & 68.89 & 10.05 \\
\hline 11.00 & -21.76 & 22.52 & 67.48 & 64.52 & 10.55 \\
\hline 11.50 & -14.26 & 16.15 & 73.85 & 55.70 & 11.05 \\
\hline 12.00 & -6.76 & 10.81 & 79.19 & 35.84 & 11.55 \\
\hline 12.50 & 0.74 & 8.69 & 81.31 & 355.41 & 12.05 \\
\hline 13.00 & 8.24 & 11.71 & 78.29 & 318.81 & 12.55 \\
\hline 13.50 & 15.74 & 17.37 & 72.63 & 302.03 & 13.05 \\
\hline 14.00 & 23.24 & 23.84 & 66.16 & 294.42 & 13.55 \\
\hline 14.50 & 30.74 & 30.62 & 59.38 & 290.59 & 14.05 \\
\hline 15.00 & 38.24 & 37.52 & 52.48 & 288.58 & 14.55 \\
\hline 15.50 & 45.74 & 44.49 & 45.51 & 287.59 & 15.05 \\
\hline 16.00 & 53.24 & 51.48 & 38.52 & 287.24 & 15.55 \\
\hline 16.50 & 60.74 & 58.47 & 31.53 & 287.33 & 16.05 \\
\hline 17.00 & 68.24 & 65.45 & 24.55 & 287.78 & 16.55 \\
\hline 17.50 & 75.74 & 72.41 & 17.59 & 288.52 & 17.05 \\
\hline 18.00 & 83.24 & 79.33 & 10.67 & 289.54 & 17.55 \\
\hline 18.50 & 90.74 & 86.21 & 3.79 & 290.85 & 18.05 \\
\hline 19.00 & 98.23 & 93.01 & -3.01 & 292.45 & 18.55 \\
\hline
\end{tabular}


Table 2: Solar path for $21^{\text {st }}$ June, 2019 for Dutsin-Ma.

\begin{tabular}{|c|c|c|c|c|c|}
\hline $\begin{array}{c}\text { Clock Time } \\
\text { (hr) }\end{array}$ & $\begin{array}{c}\text { Hour Angle } \\
\text { (Degree) }\end{array}$ & $\begin{array}{c}\text { Zenith Angle } \\
\text { (Degree) }\end{array}$ & $\begin{array}{c}\text { Elevation Angle } \\
\text { (Degree) }\end{array}$ & $\begin{array}{c}\text { Azimuth Angle } \\
\text { (Degree) }\end{array}$ & Solar Time (hr) \\
\hline 4.00 & -127.92 & 117.70 & -27.70 & 54.83 & 3.47 \\
\hline 4.50 & -120.42 & 111.58 & -21.58 & 58.31 & 3.97 \\
\hline 5.00 & -112.92 & 105.26 & -15.26 & 61.16 & 4.47 \\
\hline 5.50 & -105.42 & 98.77 & -8.77 & 63.50 & 4.97 \\
\hline 6.00 & -97.92 & 92.16 & -2.16 & 65.42 & 5.47 \\
\hline 6.50 & -90.42 & 85.46 & 4.54 & 66.98 & 5.97 \\
\hline 7.00 & -82.92 & 78.69 & 11.31 & 68.21 & 6.47 \\
\hline 7.50 & -75.43 & 71.87 & 18.13 & 69.13 & 6.97 \\
\hline 8.00 & -67.93 & 65.01 & 24.99 & 69.73 & 7.47 \\
\hline 8.50 & -60.43 & 58.13 & 31.87 & 69.98 & 7.97 \\
\hline 9.00 & -52.93 & 51.26 & 38.74 & 69.82 & 8.47 \\
\hline 9.50 & -45.43 & 44.40 & 45.60 & 69.11 & 8.97 \\
\hline 10.00 & -37.93 & 37.59 & 52.41 & 67.62 & 9.47 \\
\hline 10.50 & -30.43 & 30.88 & 59.12 & 64.89 & 9.97 \\
\hline 11.00 & -22.93 & 24.37 & 65.63 & 60.03 & 10.47 \\
\hline 11.50 & -15.43 & 18.31 & 71.69 & 51.02 & 10.97 \\
\hline 12.00 & -7.94 & 13.32 & 76.68 & 33.36 & 11.47 \\
\hline 12.50 & -0.44 & 10.99 & 79.01 & 2.10 & 11.97 \\
\hline 13.00 & 7.06 & 12.87 & 77.13 & 329.56 & 12.47 \\
\hline 13.50 & 14.56 & 17.65 & 72.35 & 310.48 & 12.97 \\
\hline 14.00 & 22.06 & 23.64 & 66.36 & 300.75 & 13.47 \\
\hline 14.50 & 29.56 & 30.11 & 59.89 & 295.54 & 13.97 \\
\hline 15.00 & 37.06 & 36.80 & 53.20 & 292.63 & 14.47 \\
\hline 15.50 & 44.56 & 43.60 & 46.40 & 291.02 & 14.97 \\
\hline 16.00 & 52.06 & 50.46 & 39.54 & 290.23 & 15.47 \\
\hline 16.50 & 59.55 & 57.33 & 32.67 & 290.01 & 15.97 \\
\hline 17.00 & 67.05 & 64.21 & 25.79 & 290.22 & 16.47 \\
\hline 17.50 & 74.55 & 71.07 & 18.93 & 290.78 & 16.97 \\
\hline 18.00 & 82.05 & 77.90 & 12.10 & 291.67 & 17.47 \\
\hline 18.50 & 89.55 & 84.67 & 5.33 & 292.86 & 17.97 \\
\hline 19.00 & 97.05 & 91.38 & -1.38 & 294.38 & 18.47 \\
\hline
\end{tabular}


Table 3: Solar path for $22^{\text {nd }}$ December, 2019 for Dutsin-Ma.

\begin{tabular}{|c|c|c|c|c|c|}
\hline $\begin{array}{c}\text { Clock Time } \\
\text { (hr) }\end{array}$ & $\begin{array}{c}\text { Hour Angle } \\
\text { (Degree) }\end{array}$ & $\begin{array}{c}\text { Zenith Angle } \\
\text { (Degree) }\end{array}$ & $\begin{array}{c}\text { Elevation Angle } \\
\text { (Degree) }\end{array}$ & $\begin{array}{c}\text { Azimuth Angle } \\
\text { (Degree) }\end{array}$ & Solar Time (hr) \\
\hline 4.00 & -127.07 & 128.74 & -38.74 & 110.18 & 3.53 \\
\hline 4.50 & -119.57 & 121.86 & -31.86 & 110.02 & 4.03 \\
\hline 5.00 & -112.07 & 114.99 & -24.99 & 110.27 & 4.53 \\
\hline 5.50 & -104.57 & 108.13 & -18.13 & 110.87 & 5.03 \\
\hline 6.00 & -97.08 & 101.31 & -11.31 & 111.79 & 5.53 \\
\hline 6.50 & -89.58 & 94.54 & -4.54 & 113.02 & 6.03 \\
\hline 7.00 & -82.08 & 87.84 & 2.16 & 114.58 & 6.53 \\
\hline 7.50 & -74.58 & 81.23 & 8.77 & 116.50 & 7.03 \\
\hline 8.00 & -67.09 & 74.75 & 15.25 & 118.84 & 7.53 \\
\hline 8.50 & -59.59 & 68.42 & 21.58 & 121.69 & 8.03 \\
\hline 9.00 & -52.09 & 62.31 & 27.69 & 125.16 & 8.53 \\
\hline 9.50 & -44.59 & 56.48 & 33.52 & 129.41 & 9.03 \\
\hline 10.00 & -37.10 & 51.04 & 38.96 & 134.62 & 9.53 \\
\hline 10.50 & -29.60 & 46.11 & 43.89 & 141.04 & 10.03 \\
\hline 11.00 & -22.10 & 41.90 & 48.10 & 148.87 & 10.53 \\
\hline 11.50 & -14.60 & 38.63 & 51.37 & 158.25 & 11.03 \\
\hline 12.00 & -7.11 & 36.56 & 53.44 & 169.01 & 11.53 \\
\hline 12.50 & 0.39 & 35.89 & 54.11 & 180.61 & 12.03 \\
\hline 13.00 & 7.89 & 36.71 & 53.29 & 192.16 & 12.53 \\
\hline 13.50 & 15.39 & 38.92 & 51.08 & 202.80 & 13.03 \\
\hline 14.00 & 22.88 & 42.30 & 47.70 & 212.01 & 13.53 \\
\hline 14.50 & 30.38 & 46.60 & 43.40 & 219.69 & 14.03 \\
\hline 15.00 & 37.88 & 51.58 & 38.42 & 225.97 & 14.53 \\
\hline 15.50 & 45.38 & 57.07 & 32.93 & 231.08 & 15.03 \\
\hline 16.00 & 52.87 & 62.94 & 27.06 & 235.23 & 15.52 \\
\hline 16.50 & 60.37 & 69.07 & 20.93 & 238.63 & 16.02 \\
\hline 17.00 & 67.87 & 75.42 & 14.58 & 241.42 & 16.52 \\
\hline 17.50 & 75.36 & 81.92 & 8.08 & 243.72 & 17.02 \\
\hline 18.00 & 82.86 & 88.54 & 1.46 & 245.60 & 17.52 \\
\hline 18.50 & 90.36 & 95.24 & -5.24 & 247.12 & 18.02 \\
\hline 19.00 & 97.86 & 102.02 & -12.02 & 248.32 & 18.52 \\
\hline
\end{tabular}

From the tables above the results shows that the route of the sun track in the location of Dutsin-Ma is different throughout the period of study. A graph of the results obtained in each table is displayed in the figures below. The hour angle, zenith angle, altitude angle, and azimuth angles were plotted against time in the same graph. 


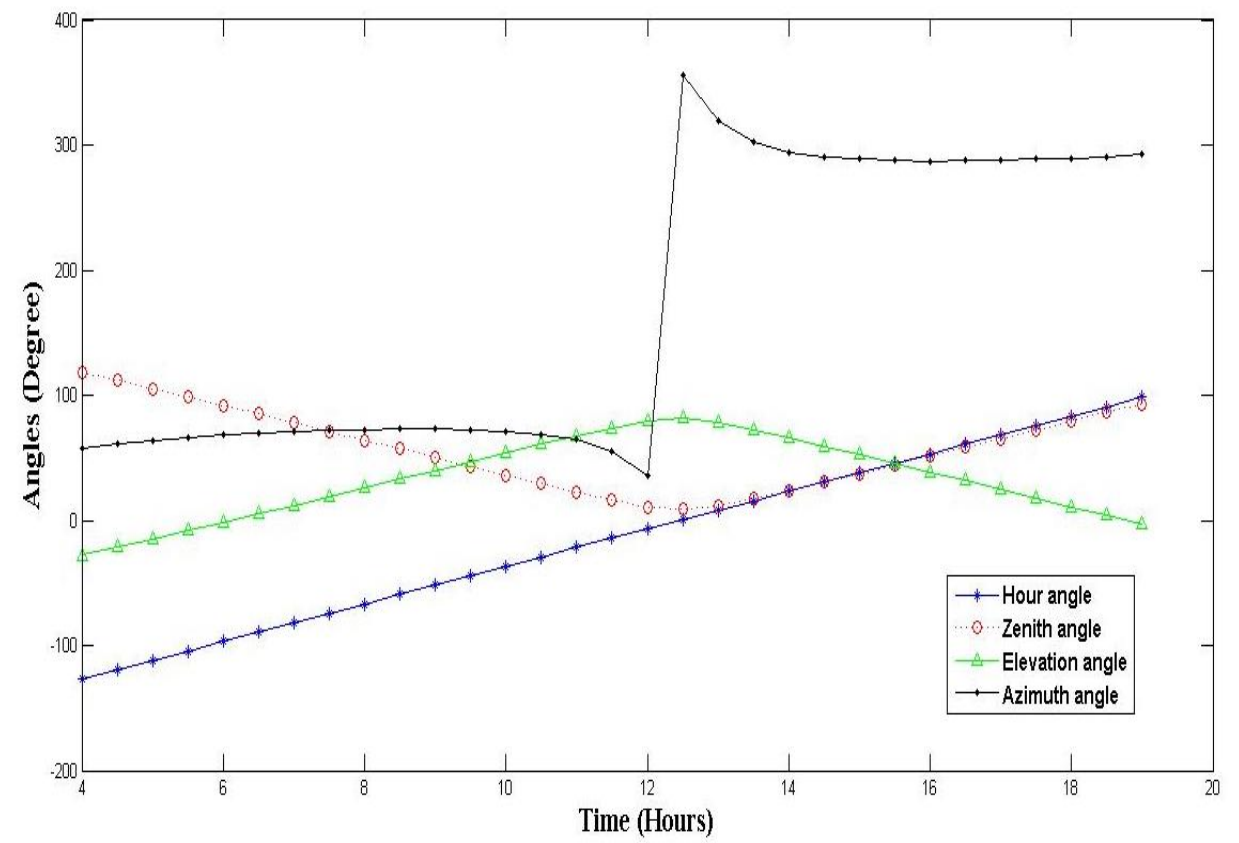

Figure 1: Sun's position for $26^{\text {th }}$ May, 2019.

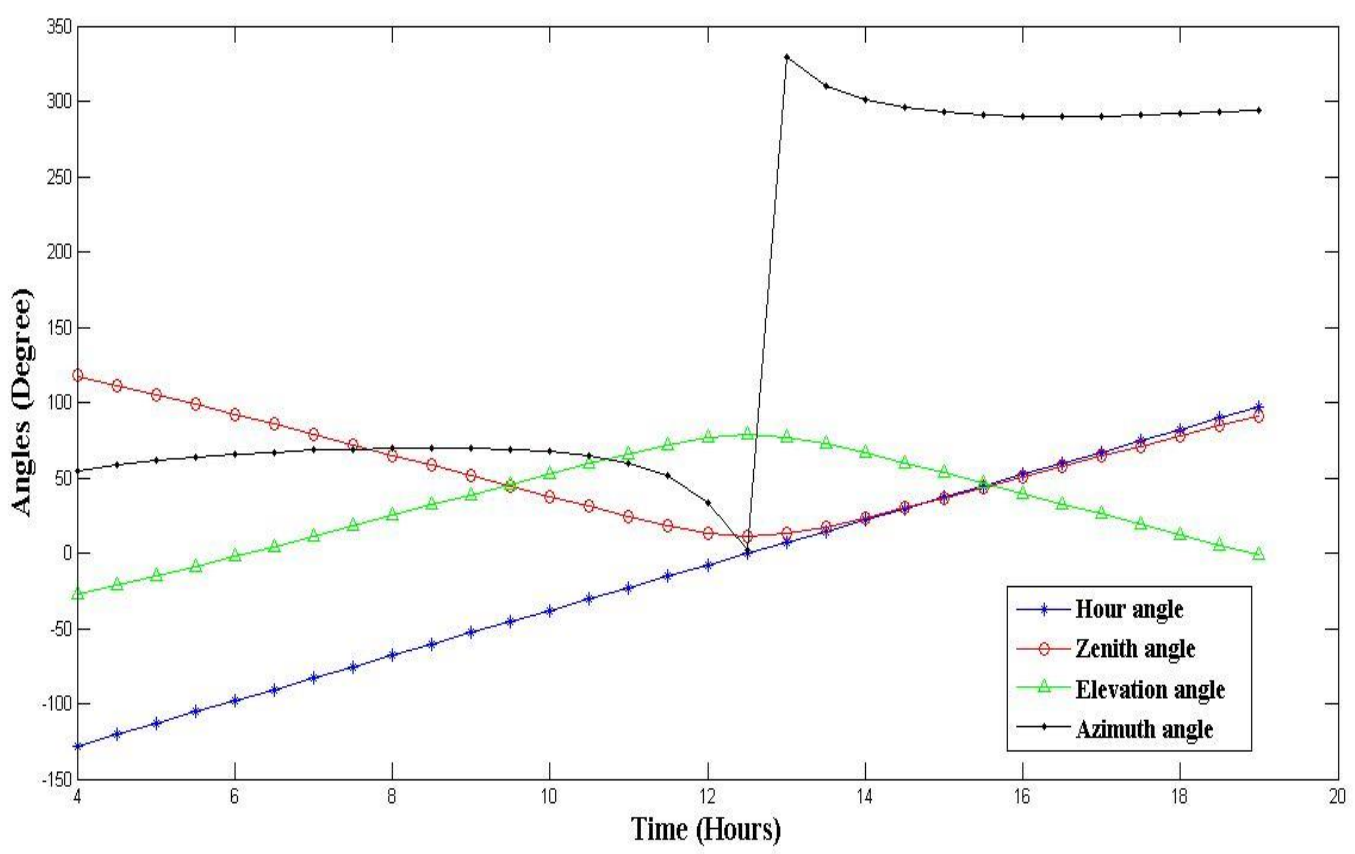

Figure 2: Sun's position for $21^{\text {st }}$ June 2019, winter solstice. 


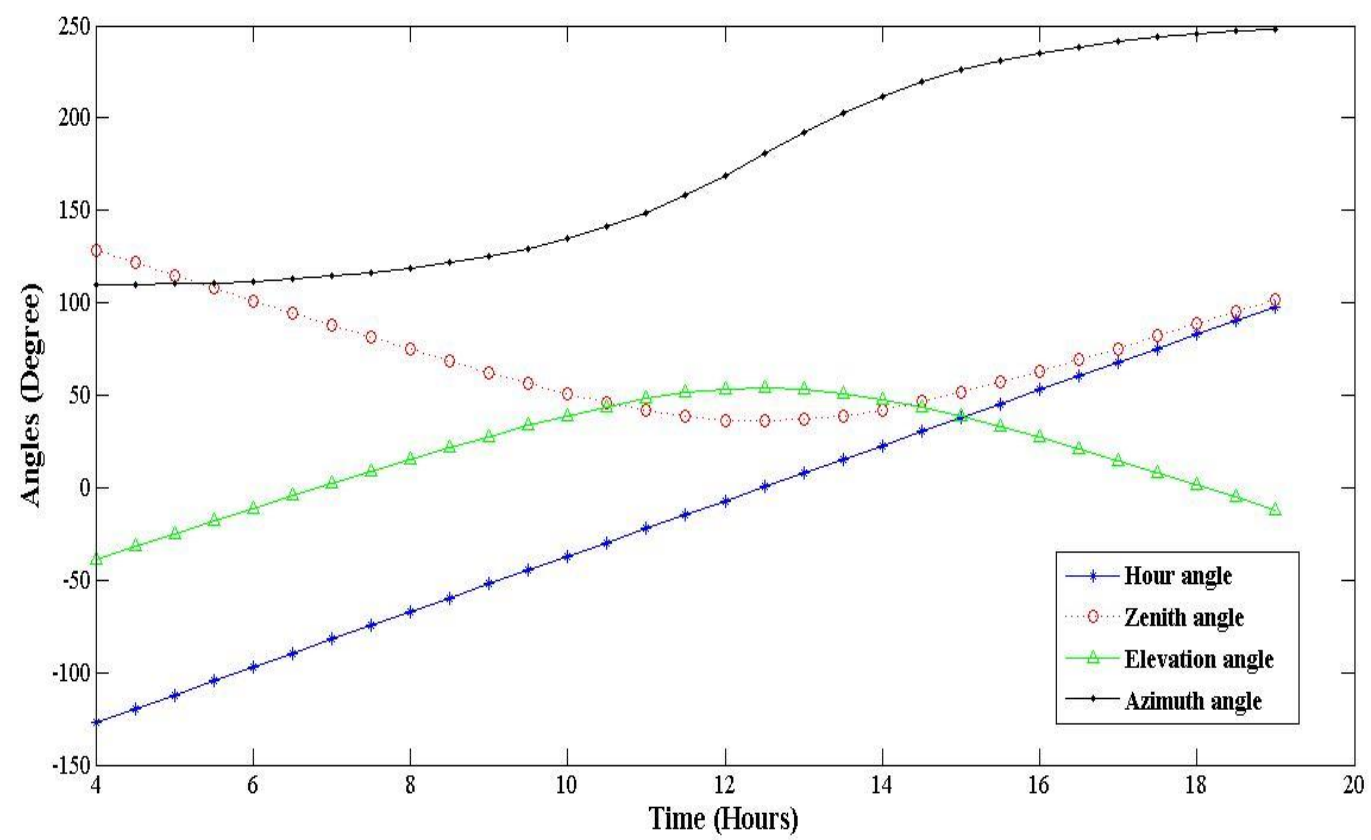

Figure 3: Sun's position for $22^{\text {nd }}$ December 2019, summer solstice.

The graphs in figure 2 and figure 3 shows the position of the sun on two days: June $21^{\text {st }}$ (winter solstice) and December $22^{\text {nd }}$ (summer solstice) in the Southern Hemisphere. They are two elevation curves on figures 2 and 3 and these curves revealed that the sun in winter ( $21^{\text {st }} \mathrm{June}$ ) is at $0^{\circ}$ at about 6:30 hours before noon, has its highest height approaching $80^{\circ}$ around noontime and about 19:00 hours is at $0^{\circ}$. The curve for summer solstice ( $22^{\text {nd }}$ December) is the same but its highest is smaller approaching $50^{\circ}$ the sunrise is later also the sunset earlier. The curves for all other days of the year within those listed above.

The azimuth angle is the angle which gives the sun's location from east to west. The two curves in figures 2 and 3 shows the motion of the sun's during summer and winter. The azimuthal angle for both curves is $0^{\circ}$ at midday (12:30). The results show that there is a significant variance of the sun route at dissimilar date or day and time of the year. It is at a different time in summer and winter, due to the summer-winter variation of time in Dutsin-Ma, Katsina state.

The two curves in figures 2 and 3 also showed that the zenith angle is minimum at 12:30 hours for both summer and winter solstices.

\section{CONCLUSION}

The ultimate applications of solar energy depend upon determining the exact position of the sun. By appropriate computation and computer programs, the path of the solar for any geographical location can be tracked. Subsequently, a piece of good knowledge about the predictions of alternative energy for any location can be developed and hence determination and, a measurement can be implemented for harnessing solar energy of that specific topographical location. The result obtained revealed that in summer solstice the elevation angle varies from $79.01^{\circ}$ to $-27.70^{\circ}$, the azimuth angle from $294.38^{\circ}$ to $-2.10^{\circ}$, and the hour angle from $97.05^{\circ}$ to $-127.92^{\circ}$, while for winter solstice the elevation angle lies in-between $53.44^{\circ}$ to $38.74^{\circ}$, the azimuth angle from $248.32^{\circ}$ to $110.18^{\circ}$ and the hour angle from $97.86^{\circ}$ to $-127.07^{\circ}$. It was concluded that the sun path of a particular location can be the same with other locations with similar latitudinal, longitudinal variations, and climatic conditions.

\section{REFERENCES}

(2007) Inspira's CPV Sun Tracking. In: Luque A., Viacheslav A. (eds) Concentrator Photovoltaics. Springer Series in Optical Sciences, vol 130. Springer, Berlin, Heidelberg. https://doi.org/10.1007/978-3-540-68798-6_11

Abdallah, S., and Nijmeh, S. (2004). Two axes sun tracking system with PLC control. Energy Conversion and Management, 45: 1931-1939. https://doi.org/10.1016/j.enconman.2003.10.007

Arbab, H., Jazi, B., and Rezagholizadeh, M. (2009). A computer tracking system of solar dish with two-axis degree freedoms based on picture processing of bar shadow. Renewable Energy, 34(4): 1114-1118. https://doi.org/10.1016/j.renene.2008.06.017

Ajayi, O.O., Ohijeagbon, O.D., Nwadialo, C.E., and Olasope, O. (2014). New model to estimate daily global solar radiation over Nigeria. Sustainable Energy Technologies and Assessments, 5:28-36. https://doi.org/10.1016/j.seta.2013.11.001

Baraya, J. T., Hamza, B. A., and Igwenagu, U. S., (2020). The effect of humidity and temperature on the efficiency of solar 
EVALUATING THE SUN'S...

FJS

power panel output in Dutsin-Ma local government area (L.G.A.), Nigeria. Journal of Asian Scientific Research, 10(1): 1-16. DOI: 10.18488/journal.2.2020.101.1.16

Chong K.K., and Wong, C.W., (2009). General formula for onaxis sun-tracking system and its application in improving tracking accuracy of solar collector. Solar Energy, 83(3): 298305. https://doi.org/10.1016/j.solener.2008.08.003

Chen, F., Feng, J., and Hong, Z. (2006). Digital sun sensor based on the optical vernier measuring principle. Measurement Science and Technology, 17(9): 2494-2498.

Chong, K.K., Siaw, F.L., Wong, C.W., and Wong, G.S. (2009). Design and construction of non-imaging planar concentrator for concentrator photovoltaic system. Renewable Energy, 34(5): 1364-1370. https://doi.org/10.1016/j.renene.2008.09.001

\section{Shehu and Baraya}

Lucien W. (2018). Basics in solar radiation at earth surface. https://hal-mines-paristech.archives-ouvertes.fr/hal-01676634

Saheli., R. (2012). Calculation of sun and tracking the path of sun for a particular geographical location. International Journal of Emerging Technology and advanced Engineering, 2: 81-84.

Tikyaa, E.V., Akinbolati, A. and Shehu, M. (2019). Assessment of empirical models for estimating mean monthly global solar radiation in Katsina. FUDMA Journal of Sciences (FJS), 3(1): $333-344$.

Yusie, R., Sunu, H., Wibowo, F. (2013). Application of solar position algorithm for sun-tracking system. Energy Procedia, 32: 160 - 165. https://doi.org/10.1016/j.egypro.2013.05.021 